\title{
AC 2010-804: CAREERME: ENCOURAGING AN ADVANCED MANUFACTURING WORKER PIPELINE
}

\section{Sandy Feola, Sinclair Community College}

Sandy Feola is the Customer Relations Manager for the NCME (National Center for Manufacturing Education) at Sinclair Community College and a part time instructor for the University of Dayton's Engineering Technology Department (since 2007) and Sinclair Community College's Operations Technology Department (since 1995), teaching industrial engineering and quality engineering curriculum. As an independent quality professional in Dayton, Ohio since 2004, She provides consultation and training to manufacturing and service organizations for performance improvement initiatives in the quality system. Over the past 25 years, Sandy has held engineering, contract support and management roles in different organizations including metal forming and machining, printed circuit board manufacturing, software development, and plastic extrusion industries. Ms. Feola has a B.S. degree in Industrial Management from Purdue University with a minor in Industrial Engineering. She is a senior member the American Society for Quality having served as a past section chair and in multiple volunteer leader positions since 1986. She is ASQ certified as a quality engineer, quality auditor, six sigma green belt, software quality engineer, hazard analysis for critical control points. She is also a member of the Institute of Industrial Engineers and is a certified Lead Auditor through RAB for ISO 9001, 14001 and 18001. 


\title{
CareerME: Encouraging an Advanced Manufacturing Worker Pipeline
}

\begin{abstract}
:
Advanced manufacturers face a shortage of skilled workers, a problem exacerbated by the negative image of manufacturing careers. To overcome the outdated view of manufacturing, the National Center for Manufacturing Education (NCME), in conjunction with the Society of Manufacturing Engineers Education Foundation (SME-

$\mathrm{EF})$, has developed a website that takes a unique approach by providing an interactive online location for students in grades 11-14, their counselors, parents, and teachers to explore careers across the country. The site www.careerME.org provides access to information at national, state, and regional levels on highly technical and lucrative advanced manufacturing careers; educational opportunities; specific companies; state-ofthe-art technologies; etc., all presented in a dynamic and interactive way our internet savvy high school and college students would expect. This paper describes the interest and motivation leading to unique implementation of a "web portal" to help improve student's interest to explore about advanced manufacturing and education leading to careers. The site also encourages educators and industry professionals to actively participate as content providers. Finally, influences to adopt social media technologies further drove development of more features that promote collaborative relationships between students, teachers, and industry. Examples of how social media concepts plan to be used used in the careerME.org website called my.careerme, are also explored.
\end{abstract}

\section{Introduction - How to Address a Need}

When the project conceptualization process started in early summer 2008 for the Society of Manufacturing Engineers (SME) - Education Foundation ${ }^{1}$, the idea was to create a web portal to show high school and college students, primarily between grades 11-14, that there are and will continue to be lucrative, high paying jobs in manufacturing; despite what is printed in the newspaper or viewed on T.V. Students should be encouraged to pursue an education in an advanced manufacturing career.

"Prepare American youth to be the next generation manufacturing workforce with the project based curricula and activities that excite and engage students in cutting edge ways" 2 . This is one of three important missions that have led SME-EF to invest in more than $\$ 3.5$ million over the past 29 years sponsoring many diverse youth programs that help students explore careers in STEM. The careerME.org web project supports this mission by helping students learn about manufacturing, from any location across the United States, through internet access.

During the design phase, our project team investigated almost twenty career exploration websites to understand the breadth, depth and how effectively the websites presented the career information. All sites offered good information; many used text descriptions and images, some displaying videos on their web pages. It was evident that these sites were created to meet very specific needs related to targeted industries, school programs, regional workforce development efforts, different careers, or trade organizations, to list just a few examples. 
For many of these sites, not necessarily all, new content was not being added very frequently; discovered when re-visiting these sites as we progressed further along our development phase. We realized early on that maintaining fresh data would be just as challenging as creating a new website.

This career exploration site needed to reflect that manufacturing is dynamic - that technologies evolve; companies figure out new ways to tackle problems; new products are developed that require new materials or different ways to make existing products better - which means that if students want to understand a complete picture, the website content must be dynamic to keep students interested. The best scenario is when students want to "come back" because they have a variety of ways to explore the information and it's evident that a site's content changes and continues to grow.

So our idea of a web portal to address this project embodied a variety of words such as dynamic, changing, relevant, participative, evolving, visual, searchable, linking, relationships, collaboration, reflective, informative, evolving, and real-time.

The careerME.org design approach was not to just create and display information about careers and school programs, but to also provide links to what could be thousands of outstanding sources, efforts, programs, organizations, demonstrations, etc. from sources that already to reflect the diversity of advanced manufacturing across the United States.

For example, a geographical navigation method for the careerME.org homepage was envisioned so that the user could "mouse over", highlight and then select a state or a region to orient the student's search results for that area. The data presented would relate to that geographic location. Students could start their exploration in a region and get back a manageable set of results related to that area. They could then change their search area to another location by re-visiting the geographic navigation box, quickly move to another location, select and enter a search to present results for that regional/state. Instead of displaying the hundreds of thousands of hits typically returned from a Google search, the careerME.org result set presented to a student is specific to the content being addressed for that careerME.org page.

The Homepage's graphical layout was designed to "grab" the user's attention through the career profile's image and links. This home screen is divided into five distinct components to present the story about a real person who works in an advanced manufacturing field, from any industry. The profiles' links connect to interview responses about their work experience and projects.

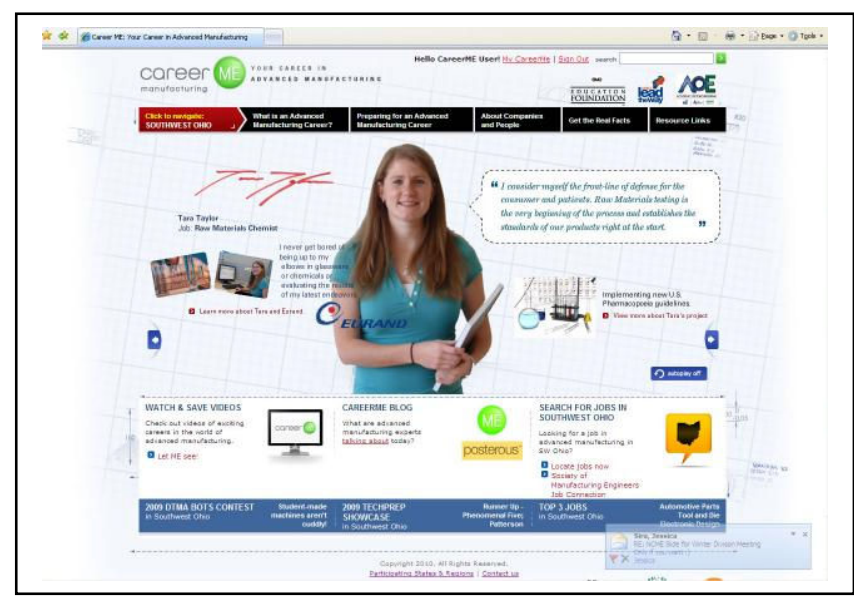

Figure 1. Interactive homepage from SW Ohio region

The career profile image and signature are also captured along with a personal quote that demonstrates that they are not a marketing image for effect. Two blue arrows at the right and left edge of the homepage can be used by an impatient viewer to quickly "click" and move back and forth through the profiles instead of waiting for the page to automatically rotate forward to the next career image every few seconds. 
The tabs above the career profile take you to lower-level web pages to present content about manufacturing careers, links to education programs available to prepare for careers in manufacturing, more companies and employees along with news stories, videos and great resource links.

Finally, the next development phase is underway that goes beyond career exploration through the Web. This newest functionality was requested by the students that originally pilot tested the careerME.org application - to have an environment where they could do more than read about companies, careers or manufacturing education programs, but have a place to collaborate and interact with companies in their area. The my.careerme feature is modeled after popular social networking sites so that students, educators, and industry professionals already familiar with social media applications can quickly learn how to use this application. The goal of the my.careerme space is to provide a separate web area so teachers and manufacturing organizations can be comfortable about networking with students. The students and teachers control who, what, where, when, etc. communication between their classmates, peers at other schools, or other professionally sponsored groups for example. Just like manufacturing companies need to stay up to date with the latest technologies that impact their products and processes, this new media networking area provides an opportunity for company mentors to get connected in a controlled space to communicate with the future potential, bright, capable workforce coming up through the pipeline. On the flip side, students want to talk with the company mentors so they can learn what manufacturing concepts are required to succeed. The my.careerme space provides the technology platform to facilitate communication with industry representatives whether the company is in their own back yard or across the country.

\section{Developing a Web Portal - Understanding a "Best Way" to Reach Students}

Among concerns expressed by the SME-EF was that students are not choosing to enroll in educational programs to prepare them to fill advanced manufacturing related careers; careers that would need to be filled to replace a retiring workforce anticipated in this decade.

To dispel the negative perceptions students could have about manufacturing careers, the project requirements specified by SME-EF for the web portal included:

1) Description of the high skill levels needed by those who enter the field of advanced manufacturing.

2) Offer information about degree programs, scholarship, co-operative programs, and job listings.

3) Contact direction for follow-up, and to acquire additional information about education opportunities, events and opportunities to interface with local industry.

4) Customized content that leverages local resources about companies and people.

5) A front page with a national emphasis and links to examples from each of the 50 states. 
The SME-EF also suggested benchmarking sites that demonstrated desirable characteristics representing some of their needs, but no specific one site satisfied all goals related to their mission for manufacturing education and career opportunities that they envisioned.

Although not a specifically stated requirement, there was a perception that unless the website content was interactive and visually stimulating (as opposed to displaying text around static images on linked pages), students would not be likely to "stop" at the website for any amount of time. And, if they did stay and spend time searching through the content, would not be likely to come back to use the site in the future as they followed their chosen path of study.

\section{Using Web Technology}

Toward the latter half of this decade, web-based software development tools for graphic software design available to developers provide a powerful resource to develop complex, interactive applications. Advances with hardware and devices make it easier to implement graphic solutions meeting system performance students have come to expect today.

Use of the Web to supplement an education experience has become more accepted by schools as better applications and technologies improve the user's learning experience. Searchable content continues to grow at an exponential rate as has the quality of the content and how it is presented to the user. There's no doubt that using the Web as a method to learn about advanced manufacturing careers proposed by the SME-EF was an excellent way to reach students, their parents, teachers, and counselors. . $^{3,4}$

Given that this project mandated a "web portal" application for advanced manufacturing career exploration, two critical areas to address revolved around providing an effective user experience.

1) Student perception: How will the site motivate students to stay when the first page is displayed, return to visit in the future, or even better, tell their peers about the site? Provide access to quality content and display the results to make learning interesting was an important project objective.

2) Content breadth, depth and growth: How can the site be used to engage industry and educational experts represented in all states and regions? We needed a way to engage content experts who would be willing to independently add and maintain data content, and be involved to promote the site within their geographic area to the student users.

\section{Gathering Student Expectations}

A project concern was that if the homepage didn't have enough "flash" or visual elements to interest students right away, they would leave the site and not likely to continue to "click and follow" the other features in the application - regardless of how good they are. To evaluate whether this was true, the project team enlisted four high school classes and one college class to participate in user pilot testing.

This pilot activity proved to be an excellent experience that provided direct contact with our target audience. Too many sites designed by adults to be used by students, reflect the 
adult's point of view and don't take into consideration the student's web-user behavior. The piloting high school student characteristics were close to 50/50 juniors-to-seniors, 80/20 male-to-female, three classes covering engineering technology career pathway courses (Tech Prep and Project Lead the Way) to one class for a college prep pathway (Physics). The schools were located in different areas across the Dayton metro region representing economic and cultural diversity. The only college student class that had time to participate were in a Project Management course, comprised primarily of sophomores and juniors, all pursuing different engineering technology disciplines; manufacturing, industrial/quality, electrical, mechanical, and computer degrees.

We learned that when you ask students what they think, make sure you have a thick skin - ask questions, listen and take a lot of notes! The three design mock-ups presented to the pilot classes did not make the cut, sending us back to the drawing board. Ultimately, we discovered that students do prefer a visual and interactive experiences using websites but they also said that the information content (text) related to an item is just as important and that they would "read" about the topic if it was interestingly presented (e.g. dynamic, interactive, image-based, etc.).

An additional challenge, one that we didn't anticipate, was how differently high school junior and seniors responded as opposed to the undergraduate college students to the three initial designs. The college class' pilot reaction was more negative than the high school classes. Even though such a small set of students participated in the pilot activity overall, their feedback about the designs were very similar - and not favorable.

Going back to the "drawing board" resulted in a more robust application design to address what students want to find out about advanced manufacturing, re-piloted with enough positive reaction to proceed to implementation.

\section{Implementation for the Web Portal}

The best scenario possible is to expose high school students to careers through a direct experience; visit a manufacturing environment, see the production as it comes off the line, feel the vibration of machinery, watch and talk to the employees. Having the ability to touch, see, hear, and even smell the environment plus communicate with the personnel involved with the product is much more meaningful than reading about it on a website. Since a very small percentage of high school students have an opportunity to visit a manufacturing environment, the question is how to present website pages to get close to meeting that level of personal experience.

A second round of student pilot feedback from the high school classes evaluated how the content was presented. The students quickly "picked up" on the differences between the five tabs across the top that related to viewing about (1) general career information, (2) education school preparation, (3) companies and people, (4) facts about manufacturing, and (5) resource links. The students placed "high importance" on features that help them locate companies that have a track record offering co-ops or internship jobs.

The students also responded to interesting pictures that were presented on each tab's landing page. These images were dynamic (cycled every 3 seconds) but did not provide any information about why they were being displayed, how they related to advance 
manufacturing. As a result of the comments, a link to information about each picture now tells the story - about technology, education, company, facts - each tab has their own picture theme, and each state and region can create dynamic picture links to content that tell about what is happening in their area.

The next three examples demonstrate different areas in careerME.org pages a student would use to learn more about manufacturing. As each example is explained, the author recommends the reader follow along by referencing the alternative resource's URL and also use the www.careerME.org website to compare the exploration experience.

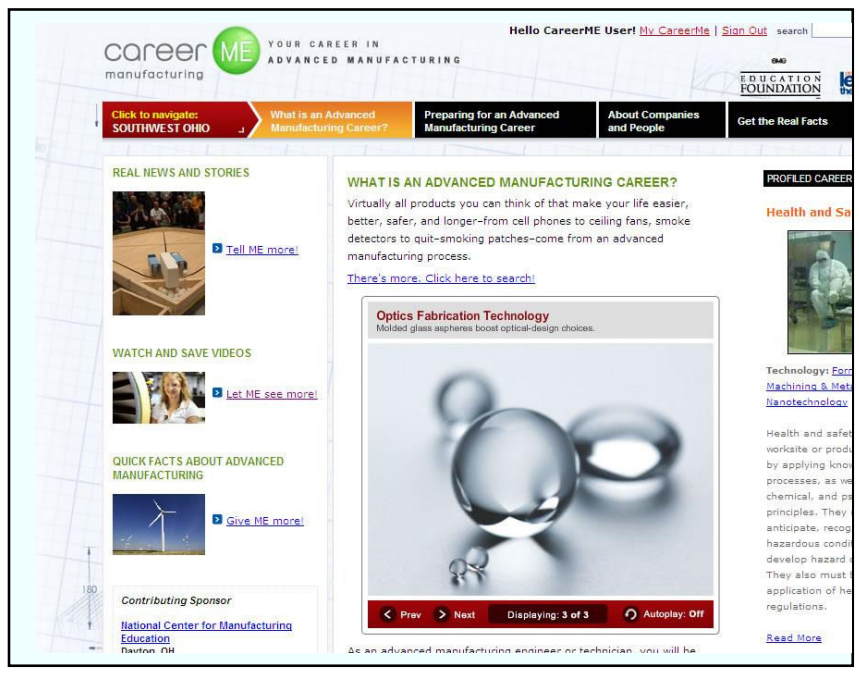

Figure 2. Dynamic image with links to source's title

\section{Example 1: Manufacturing Awareness through Company Sources}

The General Electric Aviation facility in Lynn, Massachusetts has an exceptional flash graphic web demonstration that highlights their people, a slide show image of the facility's manufacturing departments, and three videos that present a unique view about their organization. Go to the General Electric website ${ }^{5}$ to display "Meet the People behind the Innovation" that transitions into the screen with right side tabs. Mouse over the "CF34 Engine Line: Meet the People behind the Innovation" to display a rotating aircraft engine with thirty-five employee signatures. Click on any signature to display the picture of the employee, their job and a quote. Click on another tab at the left like the "Video Gallery: A tribute to GE employees" to get to the links for the T.V. Commercial and making of "Wrench". These videos present an interesting documentary view behind the scenes during the video production. This perspective exposes students to a manufacturing organization and how the employees are working together to make this engine.

But if the student were not specifically told about this URL, they would not be likely to discover the site on their own. Using search terms such as "manufacturing general electric" in an internet search returns more than 33 million hits. The student would eventually get to this URL if they had enough patience to click through the results.

In contrast, the careerME.org site provides access to the GE video in a couple of ways by clicking on the "WATCH AND SAVE" videos on the bottom of the homepage when in the United States geographic area, or by clicking on the "Let me see more" link to the right side when in the student is in the other tabbed areas such as "What is an Advanced Manufacturing Career?".

Students in Lynn, Massachusetts (where the GE manufacturing facility is located) could ask their teacher to make a request for a plant tour, line up a job shadow mentoring experience, or possibly co-op at the facility. But this only exposes a very small subset of 
potential workforce to manufacturing. It's very unlikely that students in Ohio would be able to take a plant tour of the facility. But through the links provided on the careerME.org web portal, the GE website can be found without doing hit or miss searches using an internet search engine, and chancing across the link. The separate window that opens from the careerME.org's "Watch and Save" videos link opens a window independent of the main application so that after the student completes their "tour", they can close the G.E. window without losing their careerME.org displayed page. Shifting over to view "About Companies and People" puts students in contact with the company to explore GE's website and what GE expects from students that enter into a career field ${ }^{6}$.

As a web portal, the goal is to get the student directly to the source so they can explore content specifically designed for their objective, whether it is watching videos to learning what a company requires from students to prepare to work at that organization.

\section{Example 2: Manufacturing Education Programs}

There are several ways for students to learn about post-secondary educational programs across the country. When the student clicks on the "Preparing for an Advanced Manufacturing Career" tab, the landing page displays rotating images that cycle in a continuous loop. One of the images shows several students and their instructor working on an industry project for their class (title link above the image). Click on the image to display a separate web page with the story that explains the picture. The image title "Students working on industry projects in class" also opens the webpage source: University of Colorado at Boulder school's page, featuring the Capstone Design Conference in this website article ${ }^{7}$. From this separate browser page, the high school student can read about this program and also continue to use that school's website to continue to research this program and other school facts that would be of interest.

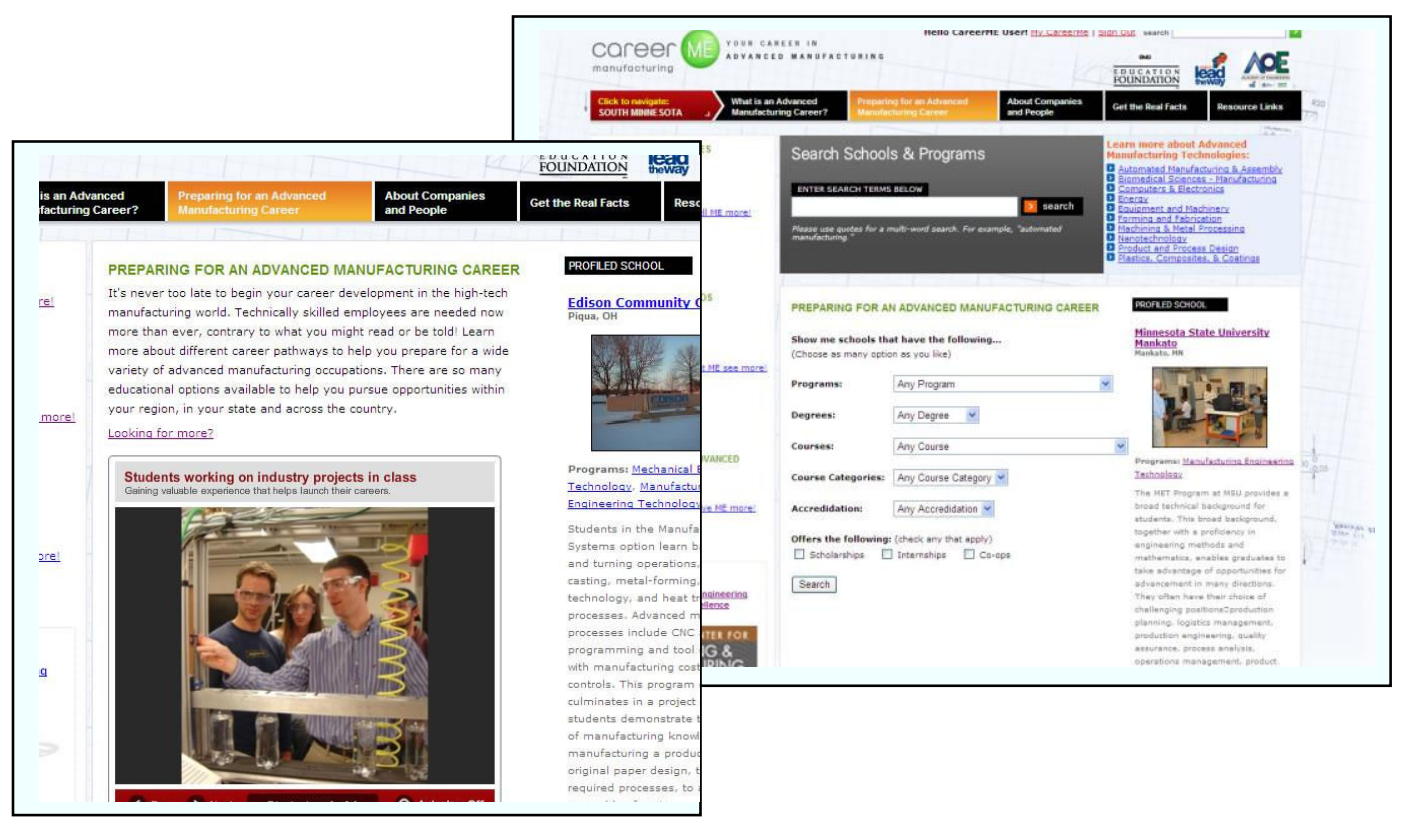

Figure 3. Landing page (left) and Search page (right) from Preparing for Advanced Manufacturing Career 
Another way to learn about manufacturing education programs from this page is by clicking the "Looking for More?" link just above the dynamic rotating images, which opens the Search page. Students that are interested scholarship opportunities can checkmark and/or select appropriate search boxes to display the list of schools that would meet this criteria.

Every school presents their website data in a completely different manner. No two school web sites present data the same way. This makes it very challenging for students to navigate between the different schools to find information about manufacturing education programs and courses. The student needs to find the school's URL first, then figure out what links take them to program content. It can be done, sometimes very quickly, but more likely, takes more than 5 minute search and investigate. If the student doesn't know what school has a manufacturing program, they don't know where to start - school programs can have different names, but offer the same variety of courses.

Schools that are added into the careerME.org database can have multiple links specifically entered to take the student directly to their educational programs. When the student enters a school name or search term(s), the results list will present the link that goes directly to the school's education programs - no need to navigate within a school's website hierarchy to figure out how to get there. When school programs are added to the database, professors are encouraged to contribute to the data, having the ability to recommend content beyond what they are able to add to their own school's site.

\section{Example 3: Advanced Manufacturing Careers}

What does a Health and Safety Engineer do? Where can I read more about this job? What schools have programs for this field? The tab for "What is an Advanced Manufacturing Career?" is designed to provide general information about all kinds of careers in manufacturing. Student's selecting a Technology link (to the right of the gray "Search Careers and Industries" box) open a window to explain more about technology and related manufacturing sectors applied in manufacturing. A variety of text, images and video sources are compiled for the student to read more and also link to good website resources.

The World Wide Web offers access to an abundant resource pool related to manufacturing careers. Hundreds of good sites that end up as "hits" from generic search engine requests originate from companies, schools, on-line libraries, professional organizations, government agencies, individuals, and many more. But how do you determine which result link being returned is a reputable source and provide relevant information to examine a career field? How many hits need to be reviewed to get to the best data?

The content offered in careerME.org becomes another source of career information, building off of the excellent sources available from across the internet and from experts in the field. Professionals working in all types of industries, for their respective career area are encourage to get involved to supplement content from their unique perspective. This has the opportunity to makes the data even more robust and dynamic. 
The career profiles on the home page also represent a first-person account about an advanced manufacturing job from a unique, real perspective. Follow the "Learn more about ..." on the homepage link to read the career profiles' responses to questions about their work experience, the education path they've taken to prepare for their job, and advice to high school students, for example. The "View more about ... project" link presents something about the work that they've supported at their company.

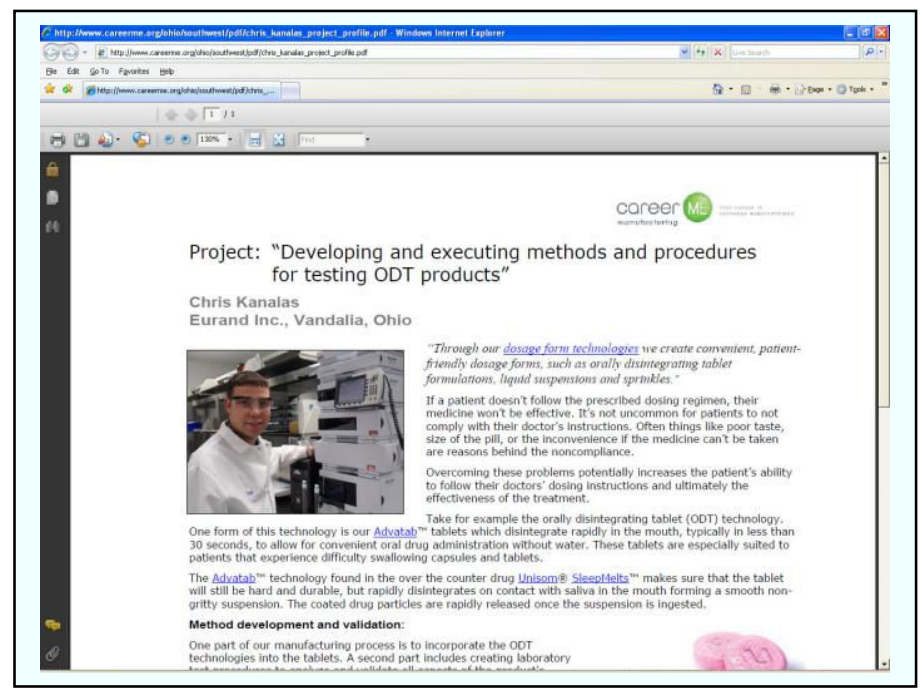

Figure 4. A Career Profile's project write-up and term links
This write-up offers an opportunity to embed html links onto the technical terms that go to a reputable content websites to help explain the technical concept presented by the career profile; terms that high school student probably would never have heard before.

Another unique opportunity available for students to be directly involved with careerME.org is to become a contributing author of a homepage company career profile.

Many high schools have job shadowing programs established for their students to learn about manufacturing careers with local companies. Job Shadowing helps extend the student's experience interacting with the company to other students by publishing their report on the site. A one day learning activity can now be shared with other students across the state or the country to read about their job shadow mentor. To participate, there should be some involvement by the teacher plus the student using the "how to" instructions to be ready to complete the careerME.org webpage components. A profile authoring document template is downloaded from careerME.org which defines a baseline set of questions the student needs to include with their own interview questions. Other webpage components include the project author template and taking photo images of their mentor.

As an outcome of most job shadowing programs, teachers typically ask their students to write a report about their experience. This is still ok to do, but the activity becomes even more meaningful by writing the report to include careerME.org questions, figuring out what terms are good to provide a learning link to an expert web source, and going through the process to edit to be proud of their work quality. Students know their job shadow mentor will read about the experience and could be critical of their work. They could even engage their job shadow mentor in the editing and review process. Accuracy of the information presented about the profile becomes more important to achieve; more than when the teacher was the only "eyes" expected to read the final report. 


\section{Expanding Content Nationally}

One important requirement defined by SME-EF was to have a national presence. The initial project focused on the southwest region data in Ohio to prove out the web portal concept. When careerME.org was released in April 2009, more states (and regions) would be scheduled to become "active" when a state/regional host partner was identified. These partners are necessary to help grow the information content for their geographic location. Active states are shaded white on the United States navigation box, and when the mouse is positioned over one of these states, the icon changes to a hand to recognize that it is ready to click to explore that state's manufacturing information.

The project model proposed to expand data content is to enlist a collaborative entity to become a State or a Regional Host Partner champion. The only logical way to expand all kinds of advanced manufacturing career content was to get active participation beyond the NCME project development team. Just the magnitude of searching for relevant data would not be feasible for one organization to manage. A potential host partner can be a manufacturing department at a university or college, another Advance Technological Education Center like the NCME, a workforce development organization, a business consortium, but are not limited to just these examples. Established relationships with industry and education partners and a mission to promote manufacturing growth are characteristics of a desired state or regional post partner.

An example of an early host regional partner is The Minnesota Center for Engineering \& Manufacturing Excellence in Mankato, Minnesota. This center leads and stimulates innovative collaboration among industry, education and allied organizations to equip Minnesota manufacturers with an educated workforce to compete worldwide. What makes the MNCEME well suited to be a host partner is that they are a consortium of academic institutions led by Minnesota State University, Mankato, in conjunction with ten two-year colleges located throughout Minnesota. The administrating host partner does not require a web expert staff member to perform this responsibility. The careerME.org website provides on-line data entry forms to enter fields that in turn populate areas on the website automatically. One click of the Submit button loads the content into the database and onto the relevant careerME.org web pages. No html developer is required. This process is used for the majority of the content displayed on the various web pages an eliminates any delay that a single website administrator would require to manage data that the regional hosting partner would be better suited to control. The data entry forms also accept images (jpg files), any document type, (e.g. doc, pdf etc. files) and links to URL's accessed from any user's browser including video source websites like YouTube.

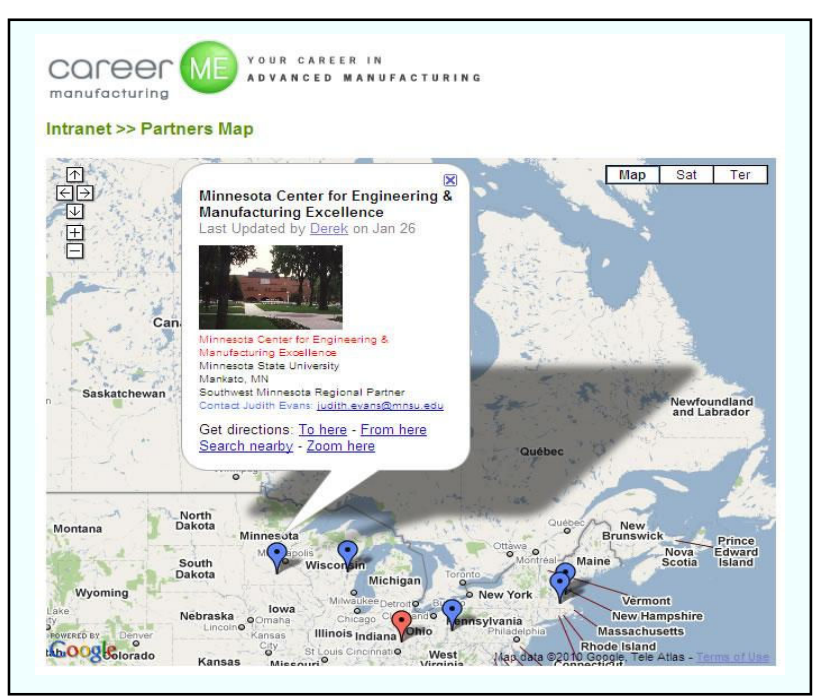

Figure 5. The regional partner map on Intranet site 
Another major goal to expand data nationally was to "not" require host partners to be responsible for software tools or any associated hardware investment. This requirement alone would be a significant barrier to enlist potential regional partners across the country to participate and engage as content providers to careerME.org. Implementing the project using a relational database, and having the ability for host partner data administrators using easy text entry forms to populate data onto the web page eliminated the need for capital investment by these organizations. The NCME houses the application source code and data storage on a main host site at Sinclair Community College to manage the database and offers staff support for flash graphics creation of the home page career profile components. But, if a host partner has the capability to support and edit the homepage profile page's content with web developer capabilities, the NCME will provide the instruction to make this option available.

\section{Managing the Data}

A data entry tool interface was created with the careerME.org application to encourage host partner members to take control of the data content - to have an easy way to add and remove data content as they think is relevant to their area. To administer data for a state or region, each host partner has their own user login and password to control or share as needed. When the host partner enters data into the fields on the forms, clicks submit, that information is populated onto the corresponding web page in the application. No need to have a website programmer manage the data presented on the site.

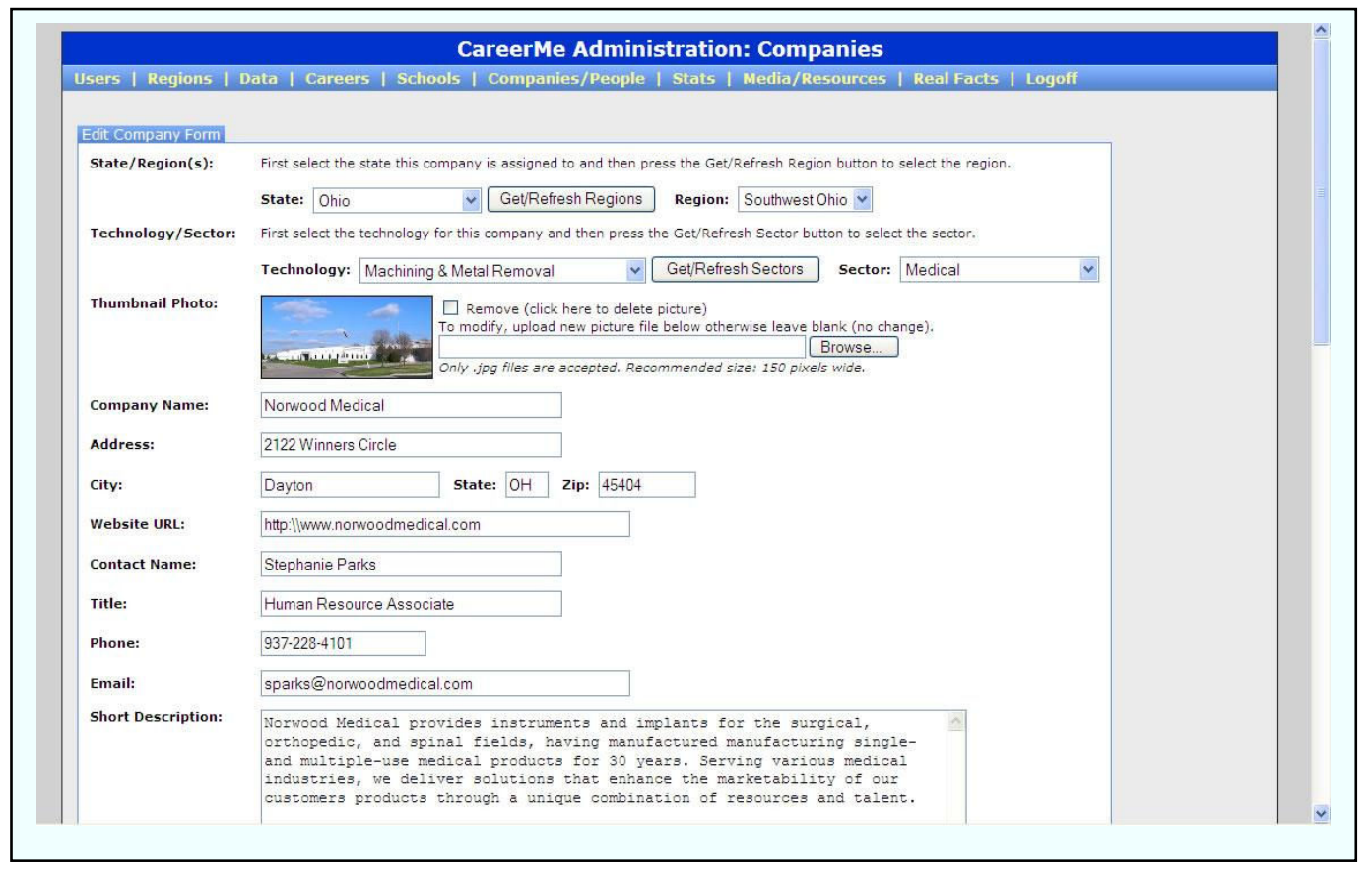

Figure 6. Top half of an Admin tool form for "Company" data entry

The host partner concept also is useful to help with marketing and publicity directly with their constituent organizations in the area. The NCME still provides resources to help host partners learn how to enter data and other data management support. 


\section{Social Media's Impact on the Student Pipeline}

Results of a study conducted by Interactive Educational Systems Design in 2009 surveyed more than 500 district technology directors around the United States finding that teachers are driving Web 2.0 adoption in schools ${ }^{8}$. Web 2.0 application type tools include online communication tools to reach out to parents and students, online multimedia resources, and tools that use teacher-generated content which is cited as the "next area of growth in the use of Web 2.0 technologies."

Extending the careerme.org web portal capabilities into the social media world with my.careerme extension was the next logical step for the education to industry workforce pipeline dialog. Social networking applications and tools offer teachers the ability to use Web 2.0 technology in the classroom and connect their students with one or more companies and industry subject matter, career profile experts. The ability to leverage this technology goes beyond the one-way search and find web portal concept by connecting students, their teachers and industry representatives in collaborative discussion.

The my.careerme space feature can be accessed through the careerme.org site or as a stand-alone application. It is designed with the Facebook application in mind; to make it easy and intuitive for students, teachers and industry members who are already familiar with and are using social networking, to quickly recognize and not require a lengthy learning curve to be productive.

The workforce pipeline now has an area to get connected by having a dedicated platform to share and collaborate. Students, teachers, and industry/company representatives create their own individual accounts just as in Facebook. But then teachers can set up their class as a "myGroup" to enable collaboration and communication between their students and even between classes across the country if desired. The SME member and industry relations managers (MIRMs) ${ }^{9}$ can be set up as a "myGroup" and identified as experts in their industry community to become accessible to students who are interested working on projects that are looking for technical input. Students can create their own project groups.

\section{Project Motivation for my.careerme}

The idea behind the my.careerme application as education-industry social networking tool came from requests by students from two high schools in the Dayton, Ohio area. The juniors and seniors liked the idea about using the careerME.org website to learn about careers, school opportunities, links to resources, and videos about "manufacturing stuff". But they also wanted a place for companies to find out about what they've accomplished. They were thinking about how to demonstrate the skills they've learned to be able to compete for a summer internship or a co-op position.

High school seniors at Dayton Public School's Engineering Technology program have participated in the Bots program ${ }^{10}$ sponsored by the Dayton Tool and Manufacturing Association (DTMA) ${ }^{11}$ the past four years. Student teams are assigned a local company sponsor who provides industry mentorship that mentor students through the designing and manufacturing concepts to develop and build a fighting robot.

These high school students learn about manufacturing tools and equipment, electronics, machining and fabrication, materials (e.g. plastics, metals), mechanics, systems integration and much more through this program. Under the guidance of their mentor's 
direction, the students develop electrical schematics, use CAD programs to design the robot, write project and status reports and more. They behaving just like they would in a role for a project team involved at a company developing a new product or manufacturing process!

Being able to use my.careerme through this process will provide a means to communicate with all of the students in the class by using "Comment" posting, or uploading a project video. The students can

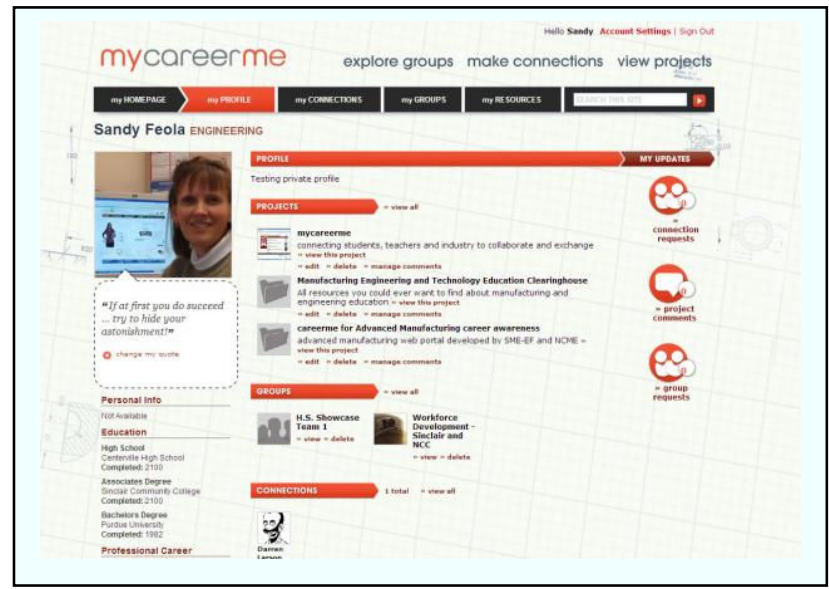

Figure 7. A my.careerme.org profile screen create videos to explain how the robot is built, or update their project milestone chart progress for example. The my.careerme.org provides an area for the students to store all of their deliverables as a "Project" so they can share between team members, their teacher and their company mentor.

Project team members plan to visit the sponsoring company during the project's schedule, but even this activity is subject to limitation because of both company's and the student's time demands. The my.careerme feature provides a platform for continuous collaboration at any time of the day without having to coordinate student transportation. Even beyond the local interchange between the student project team and the sponsoring

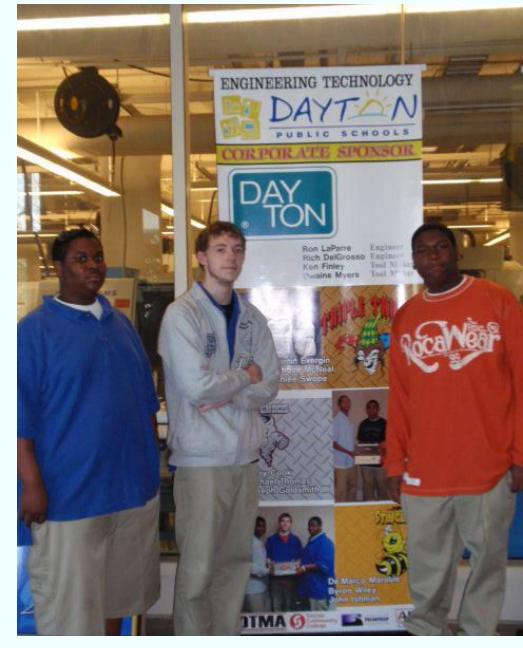

Figure 8. A Dayton Public School Engineering Technology 2009 Bots project team company, other schools classes are able to learn about the Bots project and can send a "myConnection" request (e.g. like a "friend" request) to the teacher's Group. This is the next level of collaboration, where the students and teacher can engage with other students. The Bots team gets to become the mentor! What better way to let students become their own driver into advanced manufacturing concepts by using the social media and networking skills they are very comfortable using today. The education and industry communities are able to use this application and technology platform to collaborate in a non-threatening manner.

The Engineering Technology class building the Bots is just the first example of a my.careerme networking platform for this newly released feature. The functionality is only limited by lack of ideas to put it to use starting with these three kinds of users.

\section{Conclusion}

This paper explains a web portal concept to help students become aware of advanced manufacturing through unique website offerings. Simplifying the web user experience, 
whether a student, the teacher, or a guidance counselor, is key to learning. When data are hard to find, not very accessible, boring, or less interactive for example, the desire to explore and learn also shuts down. The careerME.org site presents anything "advanced manufacturing" in an interactive manner with the model to involve host regional partners to grow the data they know about in their geographical location. Content grows and stays dynamic. Involvement by secondary and post-secondary educators with manufacturing industries, professional and trade organizations encourages the workforce pipeline using computing technologies is an excellent option to support ways that students learn today.

\section{Funding Acknowledgement}

The careerme.org project is funded by grants from the Society of Manufacturing Engineers (SME) -Education Foundation and with the support of the National Center for Manufacturing Education (NCME), an Advanced Technological Education national resource center, funded by the National Science Foundation (grant \#0802305) and Sinclair Community College.

\section{Bibliography}

${ }^{[1]}$ http://www.smeef.org/index.html accessed 1/7/2010

${ }^{[2]} \mathrm{http}: / /$ www.smeef.org/about/index.html accessed 1/8/2010

${ }^{[3]}$ http://www.netc.org/focus/technologies/resources.php accessed 3/9/2010

${ }^{[4]}$ Molner, A.S. (1997). Computers in education: a brief history. T.H.E. Journal (Technological Horizons In Education), 24(11), 63-69.

${ }^{[5]} \mathrm{http}: / / \mathrm{www}$. ge.com/autographs/\#/section() accessed 1/7/2010

${ }^{[6]} \mathrm{http}: / / \mathrm{www}$. ge.com/careers accessed 1/7/2010

${ }^{[7]} \mathrm{http} / / /$ engineering.colorado.edu/news/cue/2008/newsbytes/capstone.htm accessed 1/7/10

${ }^{[8]}$ Nagel, D. (2009). Teachers Lead Adoption of Web 2.0, but Perceptions Stifle Social Networking. THE Journal, published 04/07/09; http://thejournal.com/articles/2009/04/07/teachers-lead-adoption-of-web-20but-perceptions-stifle-social-networking.aspx

${ }^{\left[{ }^{[9}\right.}$ http://www.sme.org/cgi-bin/getsmepg.pl?/memb/mirm.htm\&\&\&SME\& accessed 1/8/2010

${ }^{[10]}$ The Dayton Tooling and Manufacturing Association (2009). Dayton Regional Bots Competition. Retrieved 1/8/2010 from http://www.dtma.org/downloads/Bots/General_Flier_2009--DTMA_Bots.pdf

${ }^{[11]}$ http://www.dtma.org/ accessed on 1/7/2010 